\title{
The origin of patients with inherited Medullary Thyroid Cancer (MTC) who are carriers of the rare exon 8 mutation (G533C) of the RET gene in Greece
}

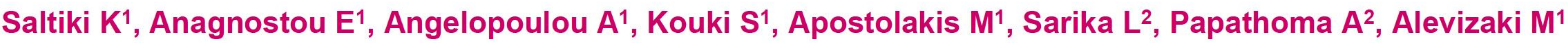

${ }^{1}$ Endocrine Unit, Dept Medical Therapeutics, Alexandra Hospital, Athens University School of Medicine and ${ }^{2}$ Dept of Endocrinology and Diabetes, ALEXANDRA Hospital, Greece

\section{Introduction - Aim of the study}

- Mutations in the ret gene $(R E T)$ are responsible for the transmission of inherited MTC.

- In recent years a high prevalence of the "rare" exon 8 mutation (G533C) has been found in patients with inherited MTC in Greece.

- The mutation has been detected in a family of Spanish origin, few French families and a case from Slovenia.

- The aim of this study was to record with more detail the place of origin of these families in the country as well as possible differences in the clinical phenotype between them.

\section{Patients - Methods}

- We analyzed the features of 44 patients with inherited MTC belonging to 22 families who were carriers of the ret $\mathrm{G} 533 \mathrm{C}$ mutation.

- Data concerning their place of origin as well as that of their ancestors were collected.

- Patients were distributed in four age groups (G1-G4) according to age at diagnosis.

Fig 1. "Hot spots" for the origin of the families carrying the exon 8 RET mutation

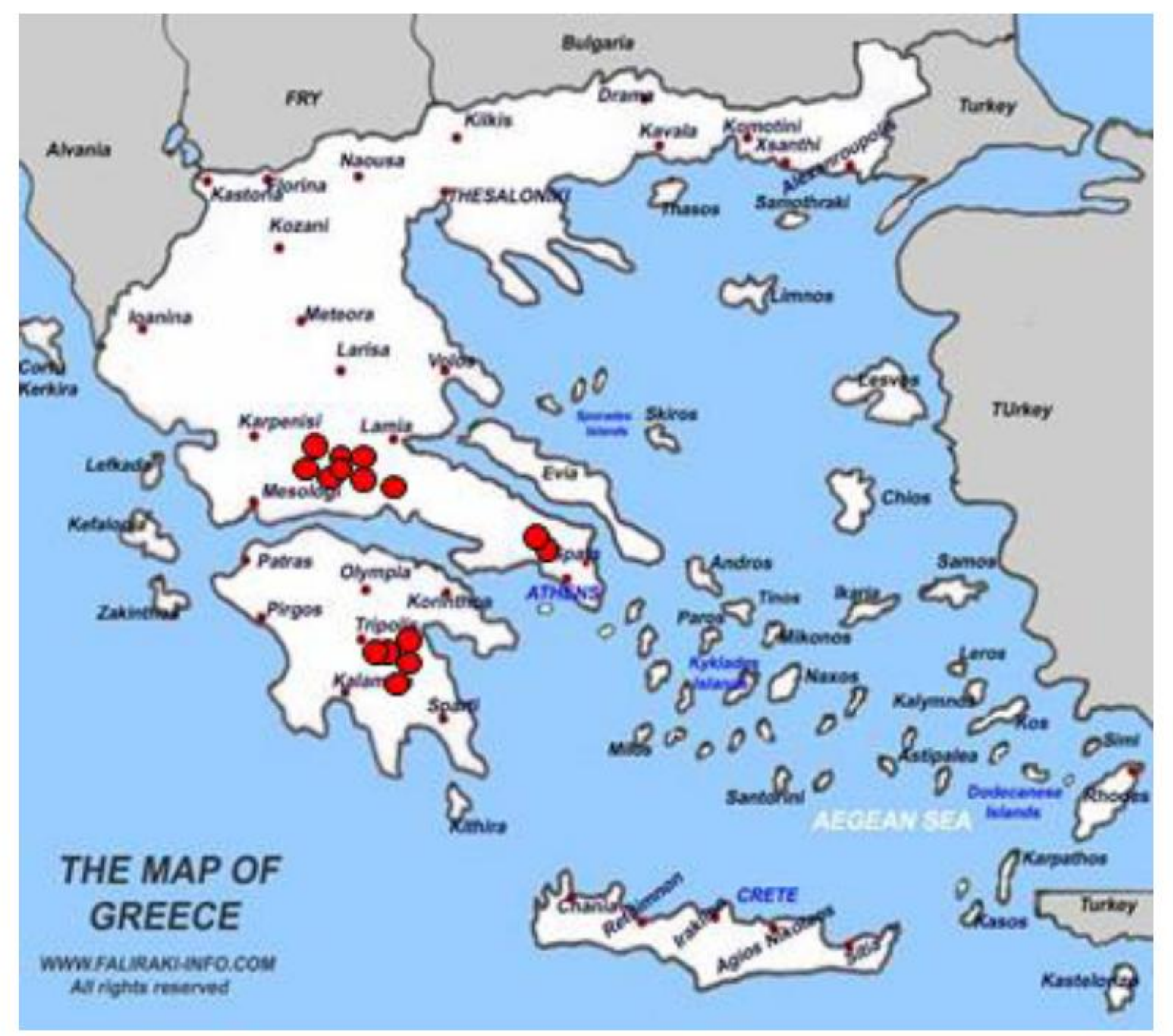

Fig 2. Origin of families carrying the exon 8 RET mutation - lake Trichonis region

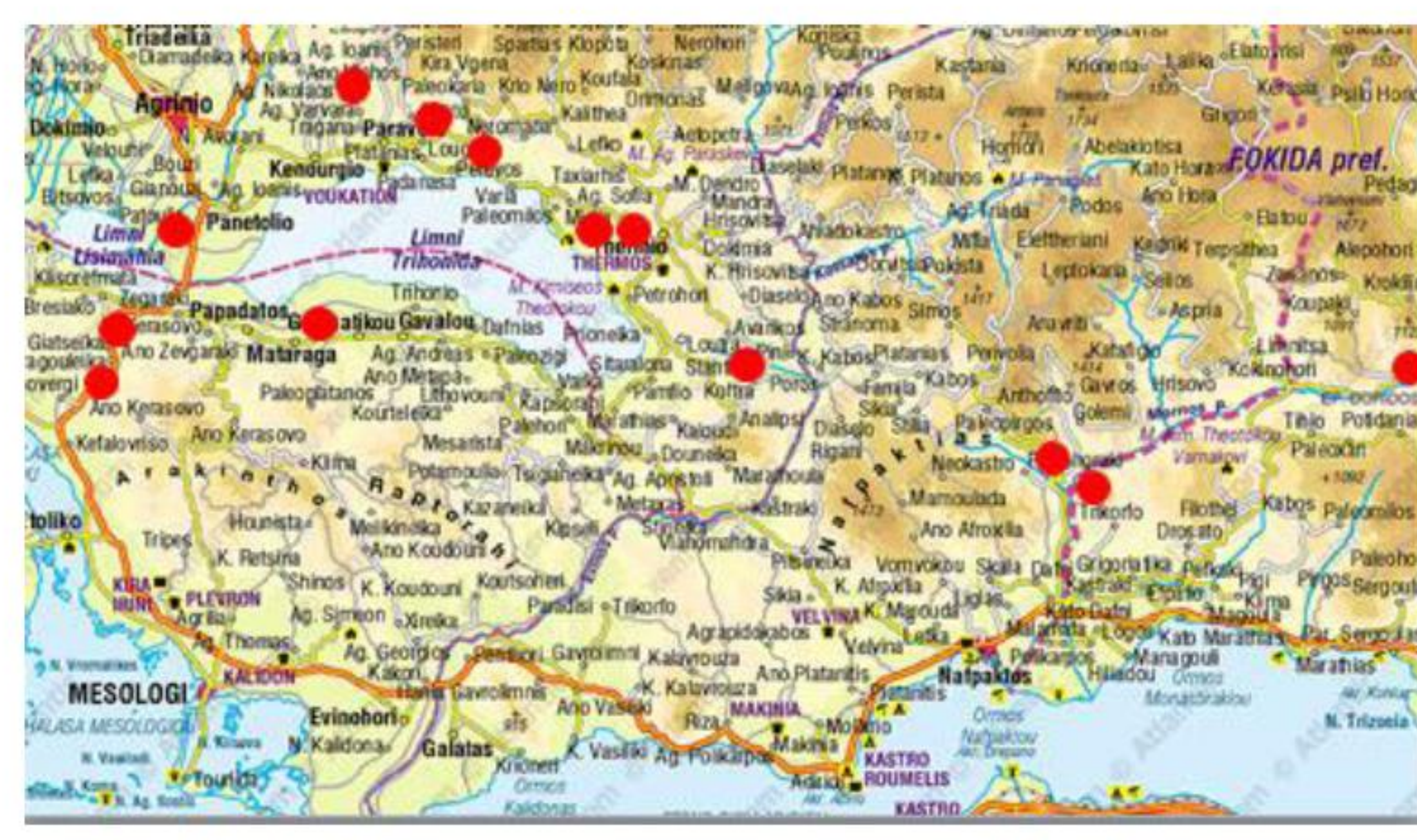

Fig 3. Origin of families carrying the exon 8 RET mutation - mount Parnon region

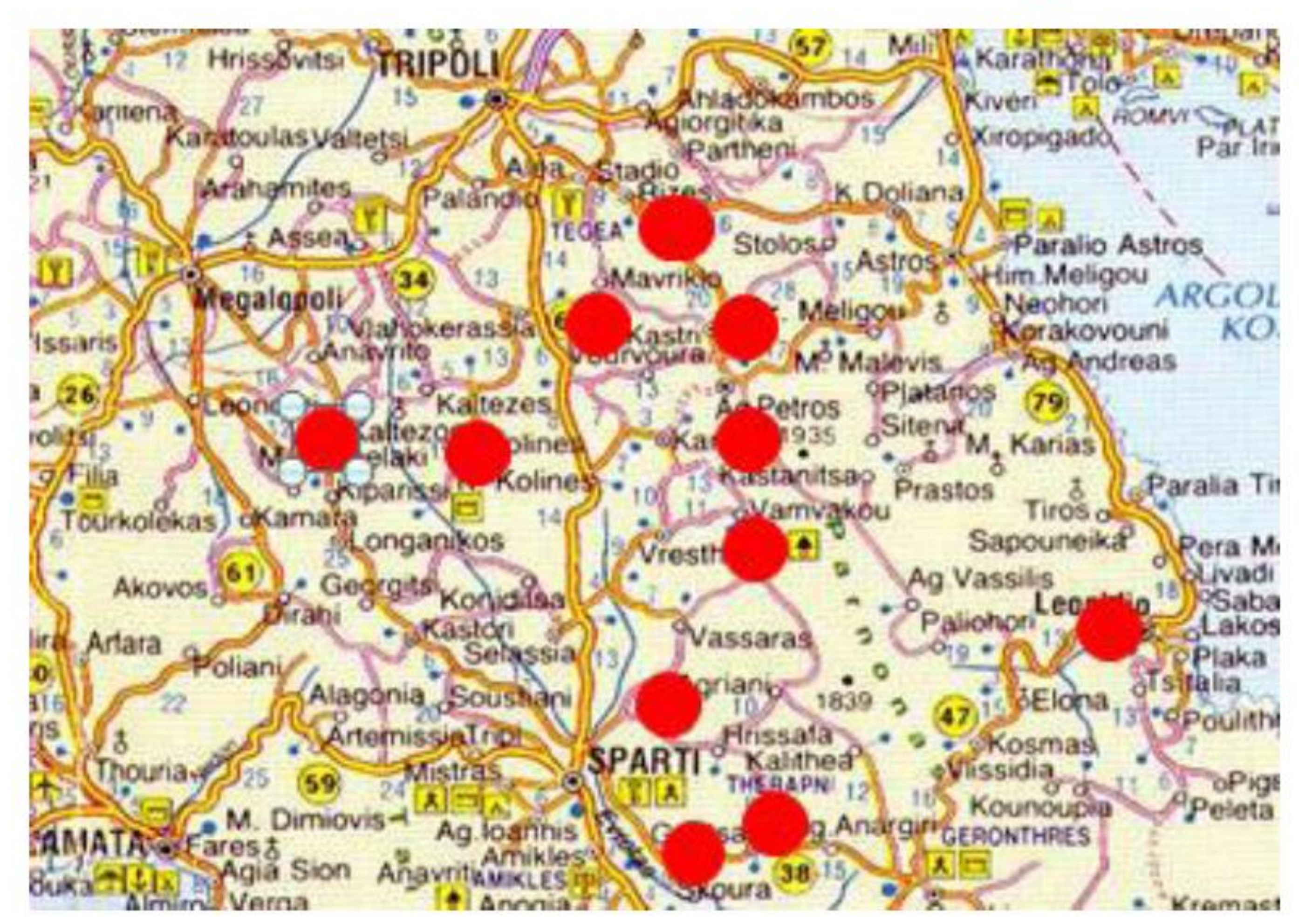

- The majority of the ret gene exon8 (G533C) carriers originate from Central/Western Greece and Peloponnese.

- Data from the international reports indicate that the exon 8 RET mutation is a "Mediterranean" mutation.

- Increased awareness for inherited disease is required for patients with apparently sporadic MTC originating from these areas, as the age at presentation is usually delayed (25-70 years).

\section{Bibliography}

\footnotetext{
Sarika H L, Papathoma A, Garofalaki M, Vasileiou V Vlassopoulou B, Anastasiou E and Alevizaki M. High prevalence of exo 8 G533C mutation in apparently sporadic medullary thyroid carcinoma in Greece. Clinical Endocrinology 20127 857-862. Fugazzola L, De Leo S Perrino M. The optimal range of RET mutations to be tested: European comments to the guidelines of the American Thyroid Association. Thyroid Research 2013 6(Sup1):S8.
}

The 4 age groups and the mean age at diagnosis are shown below

The patients belonged to 22 families.

belonged to $\mathrm{G} 2$ (table 1).

- Nine families originated from central / western Greece in an area

originated from Peloponnese (Lakonia (mount Parnon region)

- Four families from Asia Minor, all of them without any recognized familial relationship.

from the various regions.

\section{Conclusions}

